\title{
Violence Against Disabled Children Assiut governorate
}

\author{
Nessma Sh. Omer, Safaa A. Kotb, Yasser M. Elserogy \& Amira A. El-Houfey \\ Nursing Specialist in Technical Nursing Institute, Assuit University. \\ Assistant Professor of Community Health Nursing, Faculty of Nursing, Assuit University. \\ Assistant Professor of Psychiatric Medicine, Faculty of Medicine, Assuit University. \\ Lecturer of Community Health Nursing, Faculty of Nursing, Assuit University.
}

\begin{abstract}
Back ground: Children with disabilities were more likely exposed to violence than non-disabled children to be seen as having characteristics that contributed to violence. Aim of the study: To assess forms and determinants of violence against disabled children Subjects and Methods: A cross-sectional study was conducted on (800) disabled children and their care givers in Assiut Governorate. Systematic random sample techniques was used to include all subjects fulfilling the inclusion criteria. A structured interview questionnaire was used which included questions regarding the personal characteristics of children and violence. Results: The present study showed that the majority of the subjects $(79.5 \%, 66.4 \%)$ respectively were exposed to psychological and physical violence. Slightly more than one quarter $(27.6 \%)$ were exposed to sexual violence. Conclusion: it was found that approximately one third of them had bruises in their bodies from physical violence. Recommendations: An educational program should be designed for families and teachers about the effect of violence on disabled children, its prevention and nonviolent discipline techniques through mass media.
\end{abstract}

Key words: Violence, Disabled children, Physical violence, Psychological violence \& Sexual violence.

\section{Introduction}

The word violence comes from the Latin "violare", meaning to violate, injure or rape (Stanhope and Lancaster, 2008). Violence is defined as an action by a perpetrator with the intention to cause harm by the use of physical force or power, threatened or actual against oneself, another person, or against a group or community that results in injury, death, psychological harm, mal-development or deprivation (Potts and Mandleco, 2012). Spencer et al., (2005) defines "disability" as a physical or mental impairment that substantially limits one or more of the major life activities of an individual.

There are three main forms of violence: Physical violence such as hitting, kicking, beating and etc... The second form is emotional violence such as humiliation, social rejection, isolation and etc... Although emotional abuse does not leave visible injury, it is greatly serious and damaging to self esteem. The third form is sexual violence such as unwanted sexual touch, rape, verbal sexual harassment and etc...(WHO, 2011).

Community health nurse (CHN) participate to end violence against disabled children in the home, school and such intervention must be address the special need of such family and community (UNICEF, 2005). The nurse who cares for child experiencing violence must be skilled clinician who is knowledgeable about both the problem and the available community resources. In primary prevention the nurse must stop violence, abuse, or neglect before it occurs. Education plays major part in primary prevention. In secondary prevention the nurse must assess, diagnose, and treat victims and perpetrators of violence. Consideration of the safety of the potential victims is critical. In tertiary prevention the nurse must rehabilitate individuals, families, groups, or communities and includes both victims and perpetrators of violence (Nies and Mcewen, 2011).

\section{Significance of the study}

It's widely acknowledged that children with disabilities are at increased risk of becoming victims of violence. Violence against disabled children occurs at annual rates at least 1.7 times greater for these children than non-disabled peers (Jones et al., 2012).

Violence against children is a huge and serious problem worldwide. However, little is known about the magnitude of violence against children with disabilities. Worldwide an estimated that 53, 000 children less than 17 years were murdered in 2002 and about 150 million girls and 73 million boys were thought to have been exposed to sexual violence (World Health Organization (WHO), 2011). Disabled children are exposed to violence three to four times more than normal children (MacMillan et al., 2009). 
The previously published studies regarding risk of violence against disabled children are very limited in Egypt, therefore; the current study will provide information which will help to guide the design and implementation of appropriate prevention and intervention strategies targeted to those population groups.

\section{Aim of the study}

Assess forms and determinates of violence against disabled children.

\section{Subjects and methods Research design}

Descriptive cross sectional research design was utilized in this study.

\section{Settings}

This study was conducted in all schools for disabled except mental retarded schools. The study sample represented in the following schools El-Nour school for blinded pupils in El-Arbeen district, El-Amal school for females deaf and dumb pupils in ElArbeen district, El-Amal school for males deaf and dumb pupils in Assiut city, Rehabilitation center for physical disabled pupils in El- Fattah district and ElSwalim school for deaf and dumb pupils in Abnoub district.

\section{Subjects}

The target population of the study was disabled children both (boys and girls) aged approximately between 6 to 18 years. All educational levepls were included in the present study. Primary and preparatory schools were included. Primary school ranged from the first to the sixth year in all schools except deaf and dump schools has two preparatory years before enrolled in the school. Preparatory schools ranged from first to third year.

Regarding the inclusion criteria based on the definition of (WHO, 2012) of disability as individuals having a physical, sensory (deafness, blindness), intellectual or mental health impairment. So, the inclusion criteria included blind, deaf and physically disabled children that enrolled in primary and preparatory schools for disabled children in Assuit governorate.

Concerning the exclusion criteria. It included all children at El-Tarbia El - Fikria schools who had intellectual disabilities and there are about (30) deaf children who didn't learn sign's language, because it is very difficult for the researcher to find appropriate way for communication with them.

Total coverage by systematic random sample was used to include all subjects fulfilling the inclusion criteria. The total sample size was 800 from 888 students.

\section{Study tools}

Tool (1): A structured interview questionnaire for child

Was consisted of two parts:

Part (1): Included questions regarding personal characteristics of children such as (name, gender, age, education level, type of disability, etc..)

Part (2): It included questions regarding violence such as: forms of violence( physical. Psychological and sexual), places, perpetrators, child's physical complains that resulting from physical violence, child's response and child's strategies to confront violence in the previous 12 months.

Tool (2): Abd El- Tawab scale (2004) for family care giver:

To assess family sociodemographic characteristics of the studied particepants.

I-Administrative phase

An official approval letters was obtained from Dean of the Faculty of Nursing, Assiut University to general secretary of Ministry of Education who referred the researcher to the director of the department of special education which gave written approval to the directors of the previously mentioned schools. Except Physical Rehabilitation Center Permission was obtained from Directorate of Social Affairs which gave written approval to the directors of the Physical Rehabilitation Center. Each letters included permission to carry out the study with explanation of the objectives and nature of the study.

\section{Ethical Considerations}

An oral consent was taken from the children and their family care giver to participate in the study after full explanation about the aim of the study. In addition; confidentiality of data was maintained and explained for every interviewed child and their family care giver.

\section{II-Pilot Study}

After developing the tools, a pilot study was carried out on (20) children and (20) family care giver who excluded from the study. The aim of the pilot study was to test the feasibility, clarity and to estimate the required time to fill the questionnaire. According to the result of the pilot study, some necessary modification was made to avoid the ambiguity of the questionnaire.

\section{III- Data collection Phase Field work}

The researcher started to collect data from first of June to the end of December 2013. Also, during this period the researcher received the signs language training in Assuit University to communicate with 
deaf and dumb pupils. Each interview took about (2530) minutes with each pupil. Throughout the interview every answer from the pupils or family care giver was recorded according to the designed question in the form. The researcher made interview with pupils and their families care givers who agree to participate in the study during the visit. Finally, the researcher told relaxation technique for pupils after participation on the study to exclude any negative effects of remembering bad experiences.

\section{Statistical analysis}

- The collected data were coded and verified prior to data entry. The entered data were revised before conducting the statistical analysis. Descriptive statistics (i.e., frequencies, percentages, mean standard deviation, etc) was calculated using computer program SPSS version 17.

\section{Results}

Table (1): Distribution of the studied disabled children regarding their sociodemographic characteristics in Assiut Governorate, 2013, No. $(n=800)$.

\begin{tabular}{|c|c|c|}
\hline Socio-demographic characteristics & No. $(n=800)$ & $\%$ \\
\hline \multicolumn{3}{|l|}{ Age } \\
\hline$<10$ years & 231 & 28.9 \\
\hline $10-12$ years & 259 & 32.4 \\
\hline$>12$ years & 310 & 38.7 \\
\hline Mean \pm SD (Range) & \multicolumn{2}{|c|}{$11.54 \pm 3.01(6-18)$} \\
\hline \multicolumn{3}{|l|}{ Gender } \\
\hline Male & 455 & 56.9 \\
\hline Female & 345 & 43.1 \\
\hline \multicolumn{3}{|l|}{ Residence } \\
\hline Rural & 709 & 88.6 \\
\hline Urban & 91 & 11.4 \\
\hline \multicolumn{3}{|l|}{ Number of children in the family } \\
\hline $1-3$ & 186 & 23.2 \\
\hline $4-6$ & 503 & 62.9 \\
\hline$>6$ & 111 & 13.9 \\
\hline Mean \pm SD (Range) & \multicolumn{2}{|c|}{$4.79 \pm 1.78(1-14)$} \\
\hline \multicolumn{3}{|l|}{ Birth order } \\
\hline First & 137 & 17.1 \\
\hline Second & 200 & 25.0 \\
\hline Third & 198 & 24.8 \\
\hline Fourth & 121 & 15.1 \\
\hline Fifth or more & 144 & 18.0 \\
\hline \multicolumn{3}{|c|}{ Socioeconomic level (Abd El- Tawab scale, 2004) } \\
\hline Low & 128 & 16.0 \\
\hline Middle & 561 & 70.1 \\
\hline High & 111 & 13.9 \\
\hline
\end{tabular}


Table (2): Distribution of the studied disabled children regarding the forms of physical violence in Assiut Governorate, 2013, $(n=800)$.

\begin{tabular}{|l|c|c|}
\hline \multirow{2}{*}{ \# Physical violence } & \multicolumn{2}{c|}{ Yes } \\
\cline { 2 - 3 } & \multicolumn{1}{|c|}{ No. } & 44.4 \\
\hline Beating & 355 & 34.5 \\
\hline Slapping on their faces & 276 & 30.3 \\
\hline Twisting their arm or leg & 242 & 29.1 \\
\hline Throwing them with something & 233 & 23.9 \\
\hline Hitting them by pressing on their bodies & 191 & 21.6 \\
\hline Pulling their hair & 173 & 21.0 \\
\hline Biting & 168 & 18.6 \\
\hline Restricting & 149 & 18.6 \\
\hline Kicking & 149 & 17.8 \\
\hline Trapping them in a dark place & 142 & 14.4 \\
\hline Forcing them to sit or stand in an uncomfortable position & 115 & 12.4 \\
\hline Burning & 99 & 10.6 \\
\hline Threatening them with weapons or by a knife & 85 & 8.8 \\
\hline Inserting a needle in their bodies & 70 & 4.5 \\
\hline A bad taste put in their mouth & 36 & 4.0 \\
\hline Depriving of food & 32 & 31 \\
\hline Muting their breath with their hand or pillow & 27 & 3.9 \\
\hline Depriving of sleep & 25 & 3.4 \\
\hline Forcing them to smoke & 8 & 3.1 \\
\hline Cutting their hair & & 2.0 \\
\hline Forcing them to take illegal drugs & 16 \\
\hline
\end{tabular}

\# More than one answer was allowed to be reported in the child's answers.

Table (3): Distribution of the studied disabled children regarding the forms of psychological violence in Assiut Governorate, 2013, $(n=800)$

\begin{tabular}{|l|c|c|}
\hline \multicolumn{1}{|c|}{ \# Psychological violence } & \multicolumn{2}{c|}{ Yes } \\
\cline { 2 - 3 } & No. & \% \\
\hline Calling them out by undesirable descriptions. & 291 & 36.4 \\
\hline Reproaching them for simple mistakes. & 274 & 34.3 \\
\hline Talking with them in demanding manner. & 272 & 34.0 \\
\hline Asking them to do things without discussion. & 235 & 29.4 \\
\hline Depriving them of their pocket money. & 225 & 28.1 \\
\hline Making them feeling estranged and being unfriendly to them. & 194 & 24.3 \\
\hline Didn't listen to them when they talk about themselves. & 160 & 20.0 \\
\hline Criticizing them on the way they do something. & 156 & 19.5 \\
\hline Forcing them to do things they don't like. & 143 & 17.9 \\
\hline Interrupting them for a long period. & 127 & 15.9 \\
\hline Comparing them with others to reduce your business. & 111 & 13.9 \\
\hline Depriving them from the thing they like (picnic, a game and etc...). & 97 & 12.1 \\
\hline Making them feel the deprivation of parents' emotion towards them. & 87 & 10.9 \\
\hline Threatening them with ghosts and evil spirits. & 65 & 8.1 \\
\hline Threatening to send them out of home. & 40 & 5.0 \\
\hline
\end{tabular}

\# More than one answer was allowed to be reported in the child's answers 
Table (4): Distribution of the studied disabled children regarding the forms of sexual violence in Assiut Governorate, 2013, $(n=800)$

\begin{tabular}{|l|c|c|}
\hline \multirow{2}{*}{\multicolumn{1}{|c|}{ \# Sexual violence }} & \multicolumn{2}{c|}{ Yes } \\
\cline { 2 - 3 } & No. & \% \\
\hline Insulting them by sexual terms & 190 & 23.8 \\
\hline Forcing them to see sexual scenes & 61 & 7.6 \\
\hline Forcing them to touch the abuser's genitals & 38 & 4.8 \\
\hline Trying to embrace and kiss them & 34 & 4.3 \\
\hline
\end{tabular}

\# More than one answer was allowed to be reported in the child's answers

Figure (1): Distribution of the studied disabled children regarding their type of disability in Assiut Governorate, (2013).

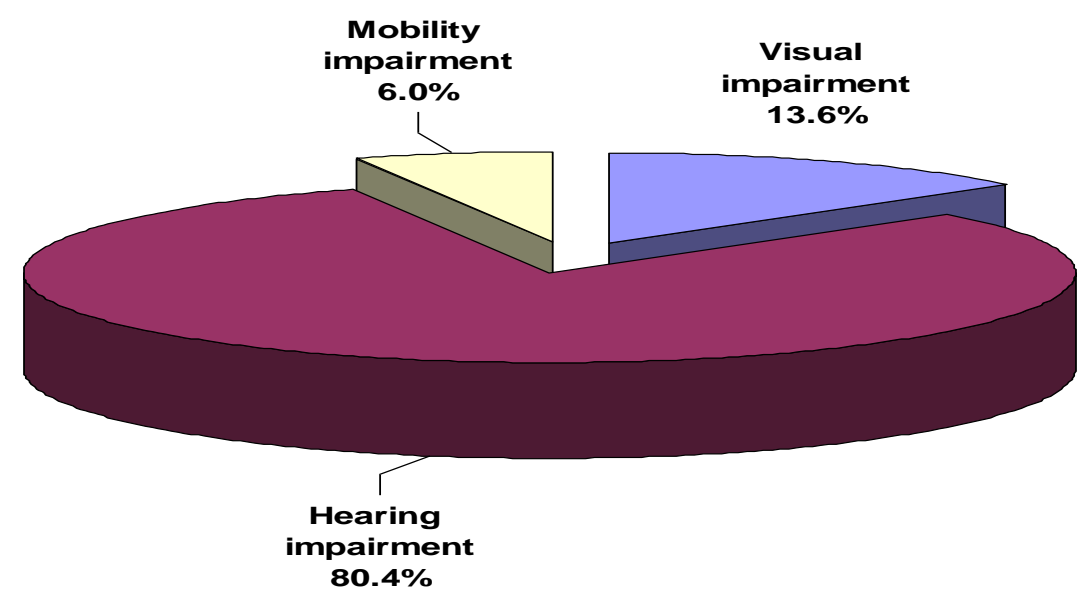

Figure (2): Distribution of the studied disabled children regarding the types of violence in Assiut Governorate, (2013).

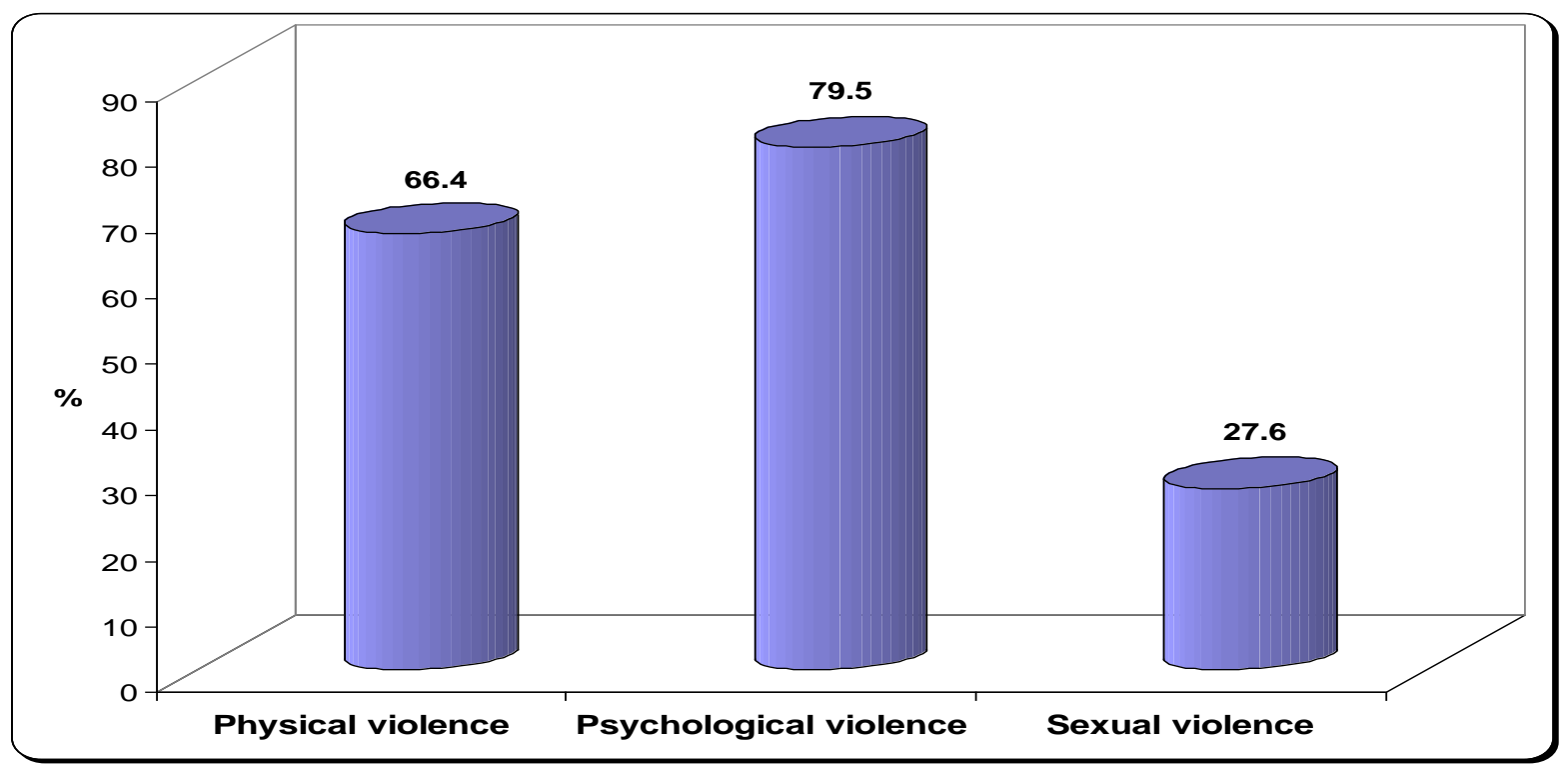


Figure (3): Distribution of the studied disabled children regarding the child's physical complains that resuting from exposure to physical violence in Assiut Governorate, (2013).

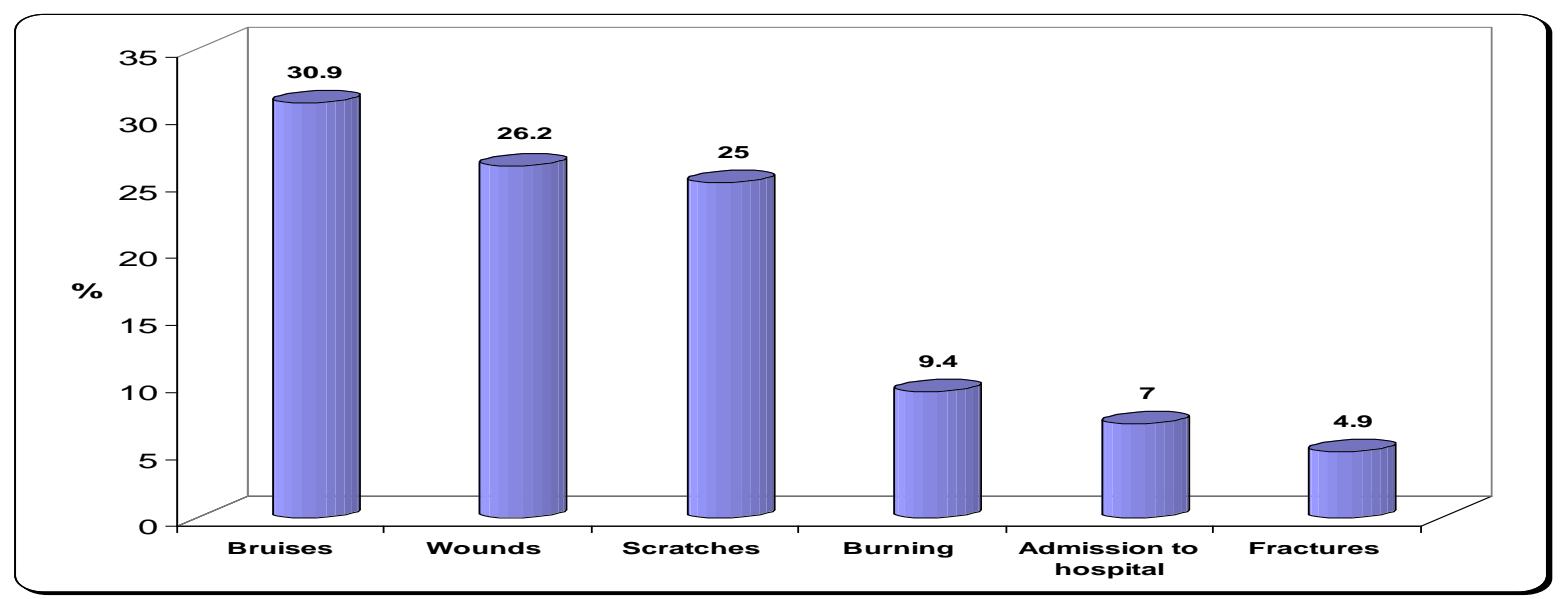

Figure (4): Distribution of the studied disabled children regarding perpetrators of violence in Assiut Governorate, (2013).

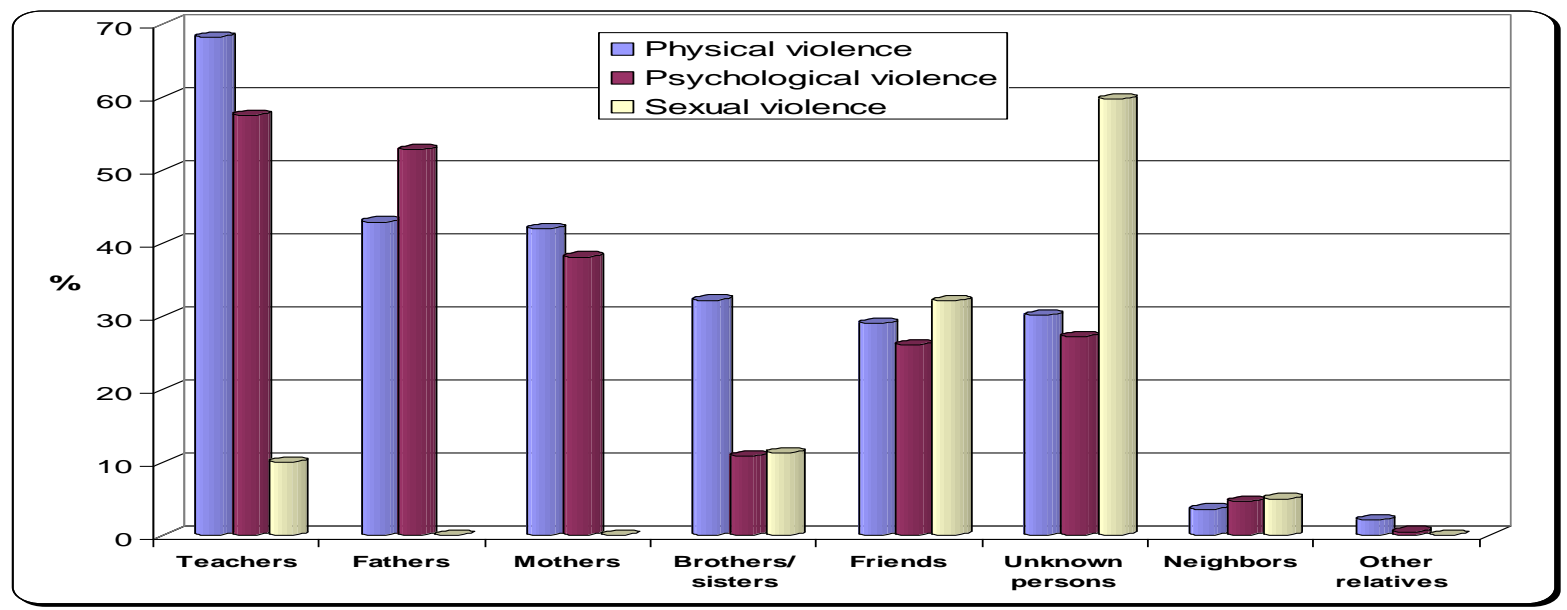

Figure (5): Distribution of the studied disabled children regarding the places of violence in Assiut Governorate, (2013).

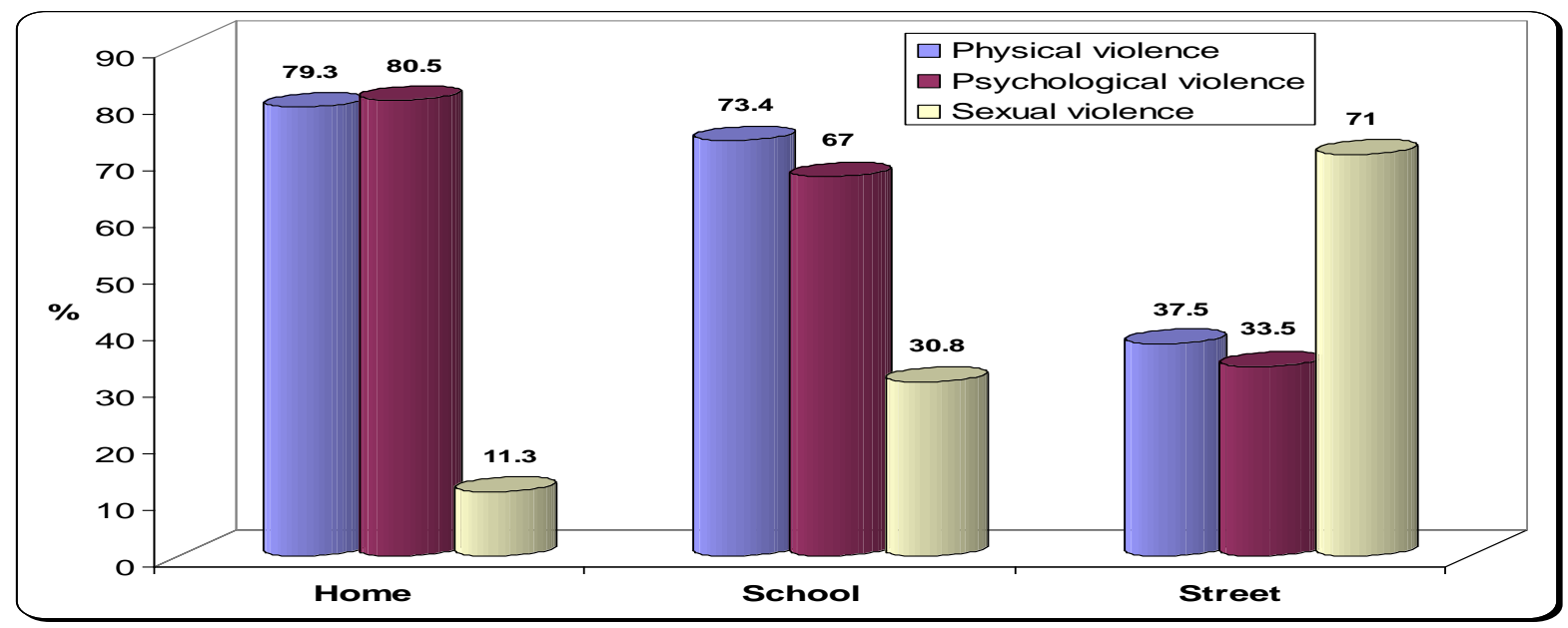


Table (1) : shows the sociodemographic characteristics of the studied disabled children. The mean \pm SD age of disabled children was (11.54 \pm $3.01)$ year. About one third $(32.4 \%)$ were aged 10 to less than 12 years. More than half $(56.9 \%)$ of the disabled children under the study were males and more than two fifths $(43.1 \%)$ were females. Regarding to residence the majority $(88.6 \%)$ of disabled children were from rural areas.

Table (2) : this table illustrates forms of physical violence pointed out that more than two fifths $(44.4 \%)$ were physically beaten while more than one third (34.5\% \& $30.3 \%$, respectively) were slapped on their faces and exposed to arm or leg twisting.

Table (3) : this table shows that the forms of psychological violence among the disabled children under the study, more than one third (36.4\%) of them were called out by undesirable descriptions, while (34.3\%) were reproached for simple mistakes.

Table (4) : It was noticed that more than one fifth $(23.8 \%)$ of the disabled children under the study were insulted by sexual terms, while $(7.6 \%)$ were forced to see sexual scenes.

Fig (1) : summarize that the majority $(80.4 \%)$ of the studied disabled children had a hearing impairment.

Fig (2) : clear the types of violence among the studied disabled children during the last twelve months. The majority $(79.5 \%)$ was exposed to psychological violence. Slightly more than one quarter $(27.6 \%)$ were exposed to sexual violence.

Fig (3) : show the child's physical complains that result from exposure to physical violence. It was manifested that approximately slightly less than one third $(30.9 \%)$ of them had bruises in their bodies, while more than one quarter $(26.2 \%)$ had wounds.

Fig (4) : It was found that more than two thirds $(68.2 \%)$ of the participants were exposed to physical violence by teachers. More than a half of participants (57.5\% and $52.8 \%$ ) were exposed to psychological violence by their teachers and fathers respectively. More than a half (59.7\%) of participants was exposed to sexual violence by unknown persons.

Fig (5) : it was found that the majorities $(79.3 \%$ \& $80.5 \%$ ) of disabled children were exposed to physical and psychological violence at home respectively. Furthermore two thirds (71.0\%) of the disabled children were exposed to sexual violence in the street.

\section{Discussion}

Disability is a chronic physical or mental health problem or a limitation of the variety of movement that can interfere with acquisition of independence and hamper the child's ability to interact with the environment (Davidson et al., 2008). According to the Egyptian Central Agency for Public Mobilization and Statistics (2006). The number of children aged between 5 to 15 years who have disability was $4.5 \%$ (The Census of Population and Housing Condition, 2006).

The findings of the present study showed that the mean \pm SD age of students was $(11.54 \pm 3.01)$ year at primary and preparatory schools, more than half of disabled children were males while more than two fifths were females. These findings may be explained by in Upper Egypt the families who have disabled girls may have shameful feeling and additionally the parents are more important for caring of males than females so that the percentage of male was appeared than females. Similar findings were reported by Abdel-Hamid et al. (2007) who conducted his studies on disabled children at Egypt about speech intelligibility in children after cochlear implementation and reported that the majority of disabled children were males, while the minority of disabled children was females.

The findings of the present clears that the majority was exposed to psychological and physical violence while the minority was exposed to sexual violence. This findings were agree with Blum et al., (2006) who conducted his study at Canada to assess health risk behaviors and protective factors among adolescents with mobility impairments, learning and emotional disabilities, the majority of them were exposed to physical and psychological violence, while the minority of them exposed to sexual violence.

The findings of the present study pointed out that more than two fifths were physically beaten. One third exposed to arm or leg twisting, while less than one third of them were thrown by something that caused pain.

These findings was supported partially with African Child Policy forum (ACPF) (2011) which conducted it's study at Ethiopia to assess violence against disabled children and reported that slightly more than one half punched, kicked and beated, less than one third deprived from food, one fifth locked or tied, (17\%) burned.

This may be explained in our culture. Teachers and family care givers used physical violence as a way to correct child behaviors, attitudes and used for learning. As well as disabled children have characteristics that contributed them to more violence. They have poor communication skills; they cannot defend themselves against attack because they are physically weak and easy to pick on. As well as a lack of social support for those who care for them as parents and teachers cause physical violence as way to express their emotion. 
In the present study, it was manifested that approximately one fifth of them had bruises in their bodies, while $(26.2 \%)$ had wounds. The findings are partially supported by Kvam (2007) who conducted a retrospective analysis of child disability and the likelihood of sexual abuse at Norway and found that $(15 \%)$ bruised, and $(3 \%)$ fractured.

The findings of the present study mentioned that more than one third of them were called out by undesirable descriptions, also more one third were reproached for simple mistakes and talked with them in demanding manner. The findings were disagree with Kudagammana, (2010) who conducted the study at Greece about defining and comprehended disabled child abuse at present time and reported that $(19.4 \%)$ of them were called out by undesirable description, (9.1\%) were reproached for simple mistakes and (14\%) were reduced their business in front of others.

These differences may be attributed to the effect of culture. In the Egyptian community most of people ignored the emotional aspect of disabled children. People may cause psychological violence according to old saying that sticks and stones may break their bones but words will never hurt them. Contrary to this old saying, psychological violence can severely damage a child's mental health or social development, leaving lifelong psychological scars.

The results of the present study revealed that more than one fifth of the disabled children insulted by sexual terms and $(7.6 \%)$ of them forced to see sexual scenes. (4.8\%) forced to touch his genitalia. The study of ACPF, (2011) reported that more than one third had been spoken to in a sexual way. (17\%) had been forced to look at sexual scenes and (16\%) forced to touch the genitals of another person.

The present study showed that the majority of disabled children exposed to physical and psychological violence at their home. Furthermore the majority of disabled children exposed to sexual violence at the street.

These findings were consistent with lee et al. (2004) who conducted his study about disabled child maltreatment in families experiencing violence at United States of American reported that the highest rate of physical violence occurs in the school. The highest rate of psychological violence occurs in the home but the highest rate of sexual violence occurs in the street.

The findings of the present study disagree with Reiter and lapidot-lefler (2007) who conducted the study on disabled children at New York to assess bullying and violence among special education students with disabilities mentioned that the majority of disabled children exposed to physical violence exposed in school. The majority of disabled children exposed to sexual violence in the street.

This can be rationalized by; Disabled children have more difficulty understanding emotions of others and social situations. This may lead to communication failure with other which helps the child to express their emotions about exposure, which in turn leads to frustration and aggression. Teachers used physical violence as a way to correct child behaviors, attitudes. There isn't report mechanism used at schools to report disabled child, teachers and family care giver to complain about violence.

The findings of the current study indicated that more than two fifths of the participants were exposed to physical and psychological violence by teachers. Furthermore, more than half were exposed to sexual violence by unknown persons.

These findings are partially supported with Oyedunni et al., (2012) who conducted his study about public health experience of violence among deaf girls at Nigeria. More than tow fifths exposed to physical violence by their Teachers. Slightly more than one third exposed to sexual violence by teachers and fathers. Further more one half of them exposed to psychological violence by fathers.

The explanation for these findings could be teaching staff who lack training and background on disability can be quick to lash out at disabled children either because of lack of job satisfaction or lack of understanding about the limitations of the children. Teachers were more contact with disabled children through establishing an internal in their school. There are no regulations and policies to stop violence against disabled children lack or absence of the social workers, psychiatrist and community health nurse in schools.

\section{Conclusion}

Based on the results of the present study, it was noticed that the majority of study sample exposed to psychological following it physical and the minority was exposed to sexual violence.

\section{Recommendations}

Based on the findings, the following recommendations are suggested:

1-An educational program should be designed by Ministry of Health and Population for families and teachers about the effect of violence on disabled children, its prevention and nonviolent discipline techniques through mass media.

2-Establishing reporting mechanism in schools that allow students, parents or care givers to complain about violence or victimization. It could be additional driving force to prevent violence. 


\section{References}

1. Abd-Hamid, O., Khatib, O., Aly, A., Morad, M., and Kamel, S., (2007): Speech Intelligibility in Children after Cochlear Implementation, American Journal Otal, 19(6):742-746.

2. Abdel Khalek, E., (2006): Magnitude of Violence, It's Determinants and Impact on Health among Secondary School Students in Assiut Governorate. Thesis Doctorate Degree in Public Health and Community Medicine, Faculty of Medicine, Assiut University, p.p1-13.

3. Abdel Tawab, A., (2004): Socioeconomic Scale to Assess Socioeconomic Status of the Family, Faculty of Education, Assiut University.

4. Achenbach, T., \& Rescorla, L., (2001): Child Behavior Checklist (CBC) For Ages (6-18), University of Verment, ed.201, pp. 1-4.

5. Blum, R., Kelly, A., \& Ireland, M., (2006): Health Risk Behaviors and Protective factors among Adolescents with Mobility Impairments and Learning and Emotional disabilities, Adolescents Health Journals, 28: 90:401.

6. Davison, M., London, M., \& Wieland, P., (2008): Maternal Nursing Women's Health across The Life Span, Women's Care: Social Issues, United State Newborn of America, ch. 13, eighteen edition, Canda, pp. 169:170.

7. Jones, L., Bellis, M., Wood, S., Huges, K., McCoy, E., Eckley, L., Bates, G., Mikton, C., and Shakespeare, T., (2012): Prevalence and Risk of Violence against Children with Disabilities: A Systematic Review and Metaanalysis of Observational Studies, 380:899-900.

8. Kudagammana, S., (2010): Defining and Comprehended disabled Child Abuse at Present Time, Journal of Forensic Medicine, Science \& Law, 1(2):30-40.

9. Kvam, M., (2007): Is Sexual Abuse of Children with Disabilities Disclosed? A Retrospective Analysis of Child Disability and The likelihood of Sexual Abuse among those Attending Norwegian Hospitals". Child Abuse and Neglect 24 (8), pp. 1073-84.

10. Lee, L., Kotch, J., \& Cox, C., (2004): Disabled Child Maltreatment in Families Experiencing Violence, Journals of Violence and Victims, 19:573-591.

11. MacMillan, H., Wathen, C., Barlow, J., Fergusson, D., Leventhal, J., \& Taussig, H., (2009): Interventions to Prevent Child Maltreatment and Associated Impairment, Lancet Journal, 373:250-66.

12. Nies, M., and McEwen, M., (2011): Community Public Health Nursing Promoting the Health of Population, violence, ch27, $5^{\text {th }}$ ed, Riverport Lane, Canda, p.p.544:559.

13. Oyedunni, S., Musibau, A., Emmanuel, O., Onyekwere, G., \& Nathaneal, B., (2012): Public Health Experience of Violence among Deaf Girls in Ibadan Metropolis, Nigeria International Journal of Collaborative Research on Internal Medicine, 4(8): 55-59.

14. Potts, N., \& Mandleco, B., (2012): Pediatric Nursing Caring for children and their Family, Growth and development of the child, ch12, ed. $3^{\text {rd }}$, USA, 393:397.

15. Reiter, S., \& lefler, N., (2007): Bullying among Special Education Students with Intellectual Disabilities: Differences in Social Adjustment and Social Skills, Intellectual and Developmental Disabilities, 45:174-181.

16. Spencer, N., Devereux, E., \& Wallace, A., (2005): Disabling Conditions and Registration for Child Abuse and Neglect: A population Based Study. Pediatrics Journal, 116:609-613.

17. Stanhope, M., \& Lancaster, J., (2008): Public Health Nursing Population - Centered Health Care in the Community, Violence and Human Abuse, ch.36, $7^{\text {th }}$ ed, Westline, Canada, p.p.832:834.

18. Sullivan, M., (2009): Violence Exposure among Children with Disabilities, Clinic Child Family Psychology, 12: 206-210.

19. The African child policy forum A., CPF (2011): Violence against Children with Disabilities in Africa; available at (www. africanchildforum.org).

20. The census of population $\&$ housing condition, (2006) : Arab Republic of Egypt, Egyptian central agency or public mobilization and statistics , available at (http://www.capmas.gov.eg/database.aspx?paren tid $=1782 \&$ free $=1)$

21. UNICF. (2005): Violence against Disabled Children, New York available at (http://www.unicef.org/videoaudio/

$\mathrm{PDFs} / \mathrm{UNICEF}$

Violence_Against_Disabled_Children_Report_D istributed_Version.pdf).

22. World Health Organization, (2011): Global Burden of Disease: available at (http://www.who.int/healthinfo/global_burden_ disease/ estimates_regional/en/index.html ).

23. World Health Organization, (2012): Children with Disabilities more likely to Experience Violence available at (http://www. who.int/healthinfo/global_burden_disease/estima tes_regional/en/index.html ). 